\title{
Enhancing the Second Step of the Trans Excision-Splicing Reaction of a Group I Ribozyme by Exploiting P9.0 and P10 for Intermolecular Recognition
}

\author{
Michael A. Bell, Joy Sinha, Ashley K. Johnson, and Stephen M. Testa
}

Department of Chemistry, University of Kentucky, Lexington, Kentucky 40506

\section{SUPPLEMENTARY MATERIAL}
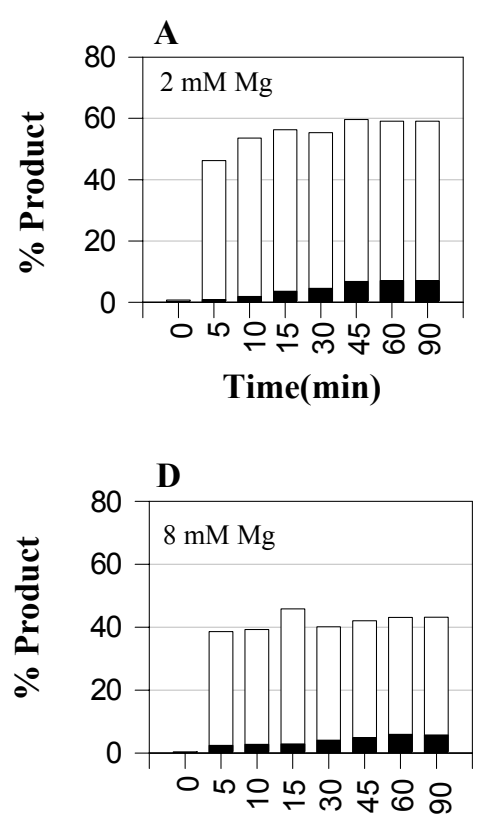

Time (min)

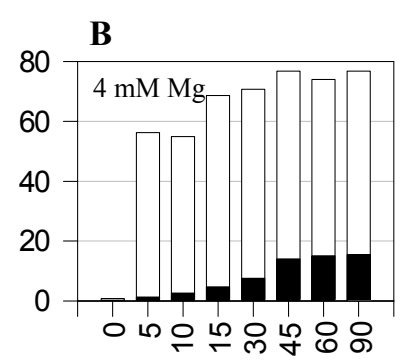

Time (min)

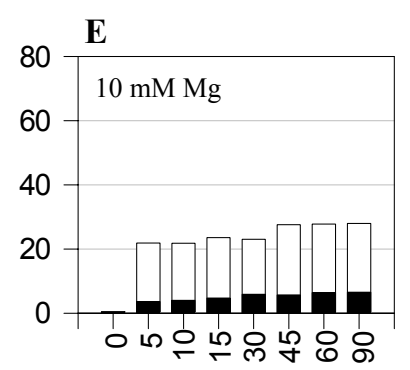

Time (min)

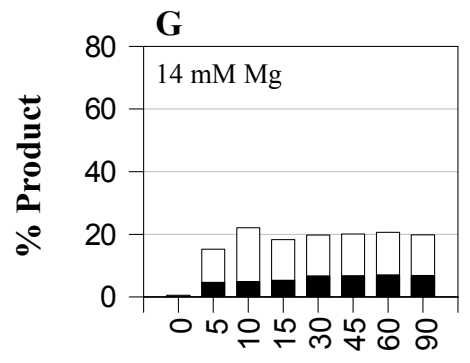

Time (min)

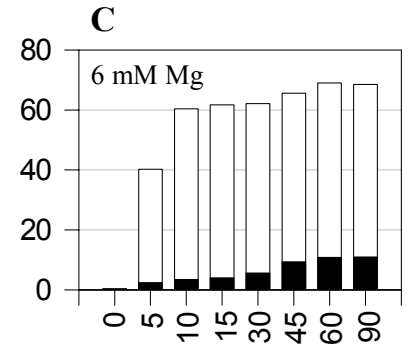

Time (min)

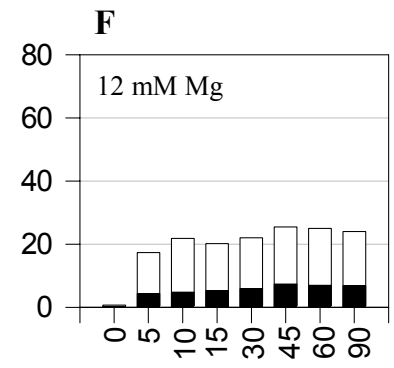

Time (min)

Figure S1. Time-Dependent Studies of TES Reactions using the 36-mer Substrate, augacucuuи(u) ${ }_{13}$ gugcucuuaaggu, and the Ribozyme, $\mathrm{rP}-8 / 4 \mathrm{x}$. Time studies were conducted in HxMg buffer, which consists of $50 \mathrm{mM}$ Hepes $\left(25 \mathrm{mM} \mathrm{Na}^{+}\right), 135$ $\mathrm{mM} \mathrm{KCl}$, and $\mathrm{x} \mathrm{mM} \mathrm{MgCl} 2$ at $\mathrm{pH} 7.5$, where $\mathrm{x}$ refers to the concentration of $\mathrm{MgCl}_{2}$ in the buffer (shown in each graph). The reactions were conducted with $166 \mathrm{nM}$ ribozyme and $1.3 \mathrm{nM} 5$ ' end labeled substrate at $44^{\circ} \mathrm{C}$. The black bars in each graph indicate the percent yield of final TES product, while the white bars indicate the percent yield of 5' exon intermediate which does not form the final TES product. The total bar length (white plus black) indicates the amount of starting material that must have undergone the first reaction step to form 5' exon intermediate. The bold letters in the substrate sequence signify the 5' and 3' exons while the normal letters signify the bridge region to be excised out. Note that in each case the first and second reaction steps are complete before $60 \mathrm{~min}$, which is our endpoint in these studies. 


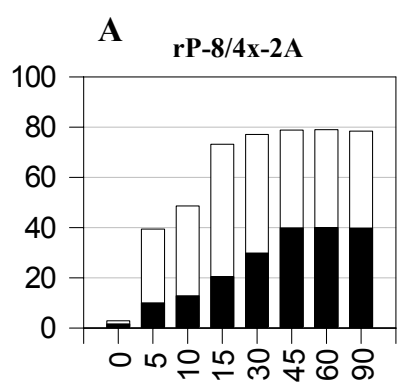

Time (min)

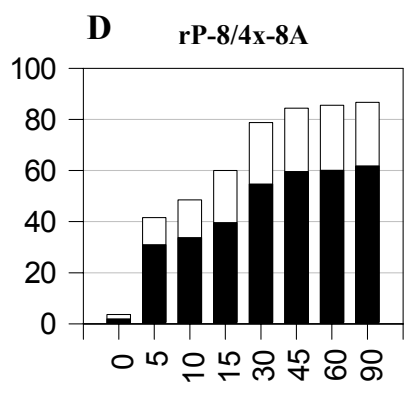

Time (min)

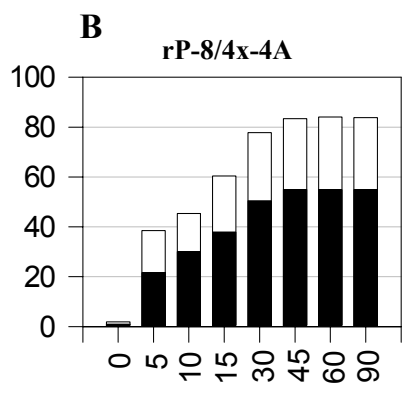

Time (min)

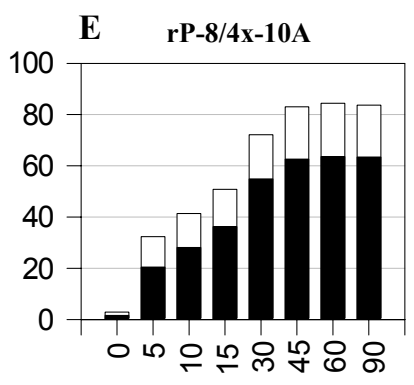

Time (min)

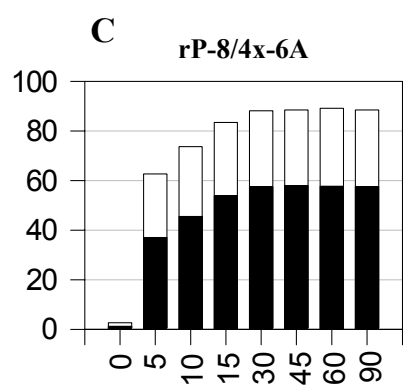

Time (min)

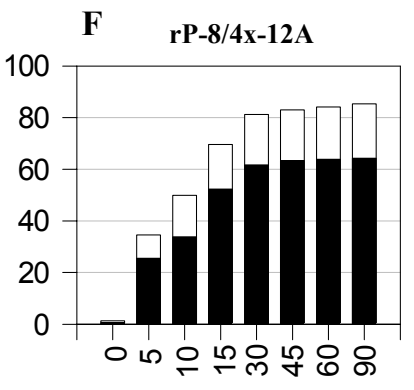

Time (min)

Figure S2. Time-Dependent Studies of TES Reactions using the 36-mer Substrate, augacucuuи(u) ${ }_{13}$ gugcucuuaaggu, and the RE2-elongated Ribozymes. Time studies were conducted in H14Mg buffer, which consists of $50 \mathrm{mM}$ Hepes $(25 \mathrm{mM}$ $\left.\mathrm{Na}^{+}\right), 135 \mathrm{mM} \mathrm{KCl}$, and $14 \mathrm{mM} \mathrm{MgCl}_{2}$ at $\mathrm{pH}$ 7.5. The reactions were conducted with $166 \mathrm{nM}$ ribozyme and $1.3 \mathrm{nM} \mathrm{5}$ ' end labeled substrate at $44{ }^{\circ} \mathrm{C}$. The ribozymes used are labeled above each graph and follow the nomenclature rP-8/4x-YA, where $\mathrm{Y}$ refers to the number of adenosines added to the RE2 region of the $\mathrm{rP}-8 / 4 \mathrm{x}$ ribozyme. The black bars in each graph indicate the percent yield of final TES product, while the white bars indicate the percent yield of 5' exon intermediate which does not form the final TES product. The total bar length (white plus black) indicates the amount of starting material that must have undergone the first reaction step to form 5' exon intermediate. The bold letters in the substrate sequence signify the 5' and 3' exons while the normal letters signify the bridge region to be excised out. Note that in each case the first and second reaction steps are complete before $60 \mathrm{~min}$, which is our endpoint in these studies. 